\title{
Systems modeling techniques for data analysis, decision making, and risk governance
}

\author{
Zachary A. Collier ${ }^{1}$. James H. Lambert ${ }^{2} \cdot$ Igor Linkov $^{3}$
}

Published online: 1 November 2018

○) Springer Science+Business Media, LLC, part of Springer Nature 2018

With this December 2018 issue, the Editorial Board of Environment Systems and Decision will have celebrated its sixth year of publication. The Editorial Board would like to thank the Springer staff for their support. We are thankful to all of the reviewers for their efforts in providing valuable feedback. And of course, we are thankful to the authors who have submitted their research over the years. Heading into the seventh year, we will continue to seek creative ways to grow the reputation and readership of the journal.

The journal has exhibited encouraging trends in metrics, including the Google Scholar metrics. The h5-index for the previous 5 years (2013-2017) rose to 18, up from 16 last year. The h5-median score is 29 . In terms of journals with the word "decision" in the title, Environment Systems and Decisions was ranked 16th. The most cited paper has 84 citations as of the writing of this editorial, with the second and third most cited having 69 and 45 citations. These metrics indicate that the research published here is having an impact.

The first article in this issue continues the year-long theme of resilience. In this paper, Woods (2018) describes the concept of graceful extensibility, or the ability of systems to adapt to changing environments. This concept is the opposite of brittleness, where systems are prone to failure when pushed beyond their operating limits. This paper, along with the others in the previous issues, collectively addresses the important and growing field of resilience research relevant to many engineering, social science, and environmental applications. The interdisciplinary nature of resilience analysis is perfect for Environment Systems and

Igor Linkov

Igor.Linkov@usace.army.mil

Zachary A. Collier

zac4nf@virginia.edu

1 Collier Research Systems, Barboursville, VA, USA

2 University of Virginia, Charlottesville, VA, USA

3 Army Engineer Research and Development Center, Concord, MA, USA
Decisions, which crosses and integrates methodological and application boundaries.

The remaining papers in this general issue cover a wide variety of topics. Zhong et al. (2018) describe and test a machine learning technique for predicting crop yields. Noori et al. (2018) develop a multi-criteria decision model for the identification of optimal locations for the construction of a new dam. In a research paper utilizing econometrics methodologies, Ibrahim (2018) explores the relationships between the financial openness, international trade, and carbon emissions of various nations. Kolian et al. (2018) analyze the policies related to the reuse of abandoned oil and gas platforms in the Gulf of Mexico, suggesting that they could be repurposed as fisheries. Di Matteo et al. (2018) review the literature on climate change vulnerability analysis, revealing several clusters of research topics. Reporting on discussions from a workshop on synthetic biology risk assessment and governance, Trump et al. (2018) present two use cases of novel technologies as examples of a proposed path forward. Finally, Ali et al. (2018) develop and demonstrate a multicriteria methodology for the ranking of waste management initiatives.

Looking ahead into 2019, Environment Systems and Decisions will feature as a special issue the proceedings of The 16th Annual Conference on Systems Engineering Research (CSER 2018), which was held in May. These papers cover a variety of topics in systems engineering and design.

As always, the Editorial Board of Environment Systems and Decisions welcomes high quality research from researchers and practitioners. We encourage original research articles, literature reviews, and perspectives papers. For inquiries, please contact the Editors-in-Chief.

\section{References}

Ali Y, Aslam Z, Dar HS, Mumtaz U (2018) A multi-criteria decision analysis of solid waste treatment options in Pakistan: Lahore 
City—a case in point. Environ Syst Decis 38(4):1-16. https://doi. org/10.1007/s10669-018-9672-y

Di Matteo G, Nardi P, Grego S, Guidi C (2018) Bibliometric analysis of climate change vulnerability assessment research. Environ Syst Decis 38(4):1-9. https://doi.org/10.1007/s10669-018-9687-4

Ibrahim MH (2018) Trade-finance complementarity and carbon emission intensity: panel evidence from middle-income countries. Environ Syst Decis 38(4):1-2. https://doi.org/10.1007/s 1066 9-018-9675-8

Kolian SR, Sammarco PW, Porter SA (2018) Use of retired oil and gas platforms for fisheries in the Gulf of Mexico. Environ Syst Decis 38(4):1-7. https://doi.org/10.1007/s10669-018-9685-6

Noori A, Bonakdari H, Morovati K, Gharabaghi B (2018) The optimal dam site selection using a group decision-making method through fuzzy TOPSIS model. Environ Syst Decis 38(4):1-8. https://doi. org/10.1007/s10669-018-9673-x
Trump BD, Foran C, Rycroft T, Wood MD, Bandolin N, Cains M, Cary T, Crocker F, Friedenberg NA, Gurian P, Hamilton K, Hoover JJ, Meyer C, Pokrzywinski K, Ritterson R, Schulte P, Warner C, Perkins E, Linkov I (2018) Development of community of practice to support quantitative risk assessment for synthetic biology products: contaminant bioremediation and invasive carp control as cases. Environ Syst Decis 38(4):1-11. https://doi.org/10.1007/ s10669-018-9710-9

Woods DD (2018) The theory of graceful extensibility: basic rules that govern adaptive systems. Environ Syst Decis 38(4):1-25. https:// doi.org/10.1007/s10669-018-9708-3

Zhong H, Li X, Lobell D, Ermon S, Brandeau ML (2018) Hierarchical modeling of seed variety yields and decision making for future planting plans. Environ Syst Decis 38(4):1-3. https://doi. org/10.1007/s10669-018-9695-4 